\title{
Electrical Machine Slot Thermal Condition Effects on Back Iron Extension Thermal Benefits
}

\author{
Fengyu Zhang, David Gerada, Senior Member, Zeyuan Xu, Chris Tighe, He Zhang, Senior Member,
}

\author{
Liang Yan, Chris Gerada, Senior Member
}

\begin{abstract}
The slot thermal condition is critical for thermal management of high performance electrical machines, due to the high heat losses and poor heat transfer ability within the slot. With a part of the backiron projected radially downwards into the slot, backiron extension (BIE) shortens the heat dissipation path from the slot coil to the back-iron and was proven to be an effective thermal improvement technique. The relationship between BIE thermal benefits and various electrical machines' parameters remains to be investigated. Based on an existing concentrated-wound machine, the relationship between the equivalent slot thermal conductivity (ESTC) and the back-iron extension effectiveness is researched in this paper. Utilizing a developed 3D thermal model, the equivalent slot thermal conductivity effects on the temperature reduction with BIE are indicated with simulation results and verified with experimental tests. BIE is reported to provide temperature reductions ranging from $48^{\circ} \mathrm{C}$ down to $18^{\circ} \mathrm{C}$ across the plausible range of ESTC values considered. Guidelines are given in the final part to suggest the situations under which BIE is more effective.
\end{abstract}

Index Terms - back-iron extension, thermal improvement, slot thermal conductivity, slot cooling, thermal network.

\section{INTRODUCTION}

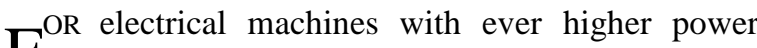
$\mathrm{F}_{\text {densities }}(\mathrm{kW} / \mathrm{L}, \mathrm{kW} / \mathrm{kg})$, and improved cost performance $(\$ / \mathrm{kW})$ developed for transport

Manuscript received January 28, 2021; revised April 19, 2021; accepted May 18, 2021. This work was supported by the Clean Sky 2 Joint Undertaking under the European Union's Horizon 2020 research and innovation programme under grant agreement number 821399. (Corresponding author: David Gerada)

Fengyu Zhang, David Gerada, Zeyuan Xu, Chris Gerada are with the Power Electronics, Machines and Control group, University of Nottingham, Nottingham, NG7 2RD, UK(email: Fengyu.Zhang1 @nottingham.ac.uk;David.Gerada@nottingham.ac.uk;Zeyuan.xu@ nottingham.ac.uk; Chris.Gerada@nottingham.ac.uk ).

Chris Tighe is with Electrical Cooling Solutions Ltd, Nottingham, NG7 2TU, UK (email: chris.tighe@electrical cooling solutions.com).

He Zhang is with the Key Laboratory of More Electric Aircraft Technology of Zhejiang Province, University of Nottingham Ningbo China, Ningbo 315100, China (email: He.Zhang@ nottingham.edu.cn)

Liang Yan is with School of Automation science and Electrical Engineering, Beihang University, Beijing, 100191, China (email: lyan1991@gmail.com) electrification, such as within aerospace, rail and automotive industries, thermal improvement is an important enabler for engineers to improve the aforementioned performance metrics $[1,2]$. The achieved temperature reduction on electrical machines directly translates to performance improvement and active material saving [3].

In transportation applications, water-jacket cooling is commonly applied to electrical machines due to the compact volume of liquid cooling with respect to forced-air cooling, with the latter requiring more space for auxiliaries such as fans and coolers [4-7]. For a conventional assembled water jacket which encloses the stator core, the heat generated within the slot is eventually removed to the coolant via the slot, the back-iron and housing [6, 8-13]. Due to the random placement of the winding in the manufacturing process, and large number of conductors, the equivalent slot thermal conductivity (ESTC) is used to capture the thermal behavior of the mishmash of slot components [14], which consist of copper, enamel, impregnation resin, and air-bubbles: in general the higher the ESTC, the better the slot thermal condition is. There are various methods to increase the ESTC value, such as using new impregnation materials. With the slot impregnation material resin replaced by epoxylite or SBTCM (a silicone-based thermally conductive material) on identical induction machines, significant temperature reduction is achieved and the current loading capability can be increased by $10 \%-15 \%$ and $25 \%-30 \%$, respectively [15]. New materials with higher thermal conductivities can also be applied to different locations/functions within the stator, such as for impregnating the conductor bundle, potting or encapsulating [16]. However, new material developments often come at an increased premium, with the impregnation-material cost in an approximate direct linear relationship with its thermal conductivity (i.e. the higher the resin's thermal conductivity, the higher its cost).

Alternatively besides new resin materials, slot cooling channels [17-21] and oil-spray cooling [22-25] are widely investigated in recent technical literature to enhance the traditional water-jacket cooling system by shortening the heat transfer path from the slot to the coolant. However, these add complexities to the 
cooling system together with the need of an extra pump as well as sealing components. Back-iron extension (BIE) with a part of back-iron extended into the slot is proposed in [6] as a simple and effective thermal improvement technique for electrical machines equipped with water-jacket cooling. Similar to the slot cooling channels, BIE mainly targets the removal of heat generated within the slot and thus it is more suitable for electrical machines where copper losses are dominant. BIE reduces the hot spot temperature in the slot by forming a shortcut heat transfer path between the slot and the coolant since the radial thermal conductivity of the lamination $(\sim 29 \mathrm{~W} /(\mathrm{m} \cdot \mathrm{K}))$ is much higher than that of the coil $(0-2 \mathrm{~W} /(\mathrm{m} \cdot \mathrm{K}))$.

However, the previous research in [6] only validates BIE thermal effectiveness for one specific value of ESTC $(0.7 \mathrm{~W} / \mathrm{m} \cdot \mathrm{K})$. Using a BIE, the experimental results in [6] verified a significant temperature reduction of up to $48^{\circ} \mathrm{C}$ at the rated power for a single specific slot material/manufacturing recipe corresponding to the aforementioned ESTC value. In practice the ESTC can take a broad range of values due to different plausible compositions of slot materials and manufacturing processes. An open research question thus remains as to whether the BIE still brings significant temperature reductions, and by how much, for a range of ESTC values which readers might encounter for their cases in hand. This paper investigates quantitatively the BIE effectiveness relationship with ESTC, in an effort to provide readers with sufficiently detailed and reproducible analysis/experimental methods, as well as reference guidelines on design choices for the slot region which is of critical importance in high performance machine design.

Firstly the ESTC determination is processed in this research, considering various commercially available resins. Then the BIE effectiveness is studied quantitatively against ESTC values corresponding to various slot compositions. Experiments are conducted to validate the relationship between the BIE effectiveness and ESTC.

Contributions of this paper include:

- For machines with different ESTC values which correspond to various slot compositions, the temperature reduction with back-iron extension is quantified and compared based on both the developed 3D thermal model as well as through experimental measurements.

- Description of sufficiently detailed analytical and experimental methods which readers can reproduce for their case-investigations. These include 3D thermal models, an improved ESTC calculation method which accounts for air bubbles and various impregnation resin materials, together with instrumented motorette setups for practical verification.

- Suitability guidelines are provided for the use of BIE in relation to the slots' ESTC.
The organization of the paper is as follows: Section II describes the thermal model based on which the research is conducted, together with the technique used to investigate the relationship between the BIE thermal effectiveness and ESTC. This analysis is experimentally validated in Section III. Finally, conclusions from this research are summarized in Section IV.

\section{THERMAL ANALYSIS}

For water jacket cooled electrical machines, heat generated within the slot is eventually transferred to the water jacket via two heat transfer paths, (i) directly through back-iron; (ii) through stator teeth first and then to back-iron. Back-iron extension (BIE) as shown in Fig. 1 by projecting part of the back-iron into the center of the slot is proposed to improve the heat transfer path for a $75 \mathrm{~kW}$ permanent magnet machine with concentrated winding in [6], with relevant data listed in TABLE 1. For a machine equipped with waterjacket cooling, the hot spot is typically located in the slot center due to low equivalent slot thermal conductivity and high heat loss. BIE forms a short-cut, for the thermal dissipation path from the coil center to the back-iron and eventually to the coolant, since the radial thermal conductivity of the lamination $(\sim 29$ $\mathrm{W} /(\mathrm{m} \cdot \mathrm{K}))$ is much higher than that of the coil $(0-2$ $\mathrm{W} /(\mathrm{m} \cdot \mathrm{K}))$. The magnitude of ESTC affects the heat removing ability of the shortened heat transfer path which BIE forms.

On the other hand, the BIE and surrounding groundwall insulation occupy space in the slot which would otherwise be available for the winding, reducing the copper fill factor by $9.6 \%$ from 0.4572 down to 0.413 . Meanwhile, the flux leakage through BIE translates to a higher current for the same output torque. The reduced copper area and increased current demand can increase the copper losses, depending on the magnitude of the temperature benefit. The optimization of BIE dimensions is thus a trade-off study and different geometries of BIE were investigated and analysed based on the thermal benefits, considering multidomain factors, including the copper filling factor reduction and the additional flux leakage due to the BIE in [6]. An optimum BIE having a $2.2 \mathrm{~mm}$ width and a depth equal to the slot depth was derived and experimentally validated, as shown in Fig. 1. This paper is based on the optimized BIE geometry and investigates the relationship between the BIE effectiveness and the ESTC.

This section presents a comprehensive thermal analysis of the correlation between ESTC and BIE thermal benefits. Firstly, a simple improved way to calculate the ESTC is proposed, considering all the slot constituent elements. The ESTC is then applied in the thermal model developed for the test segments, followed by the correlation investigation between the ESTC and the BIE effectiveness. 


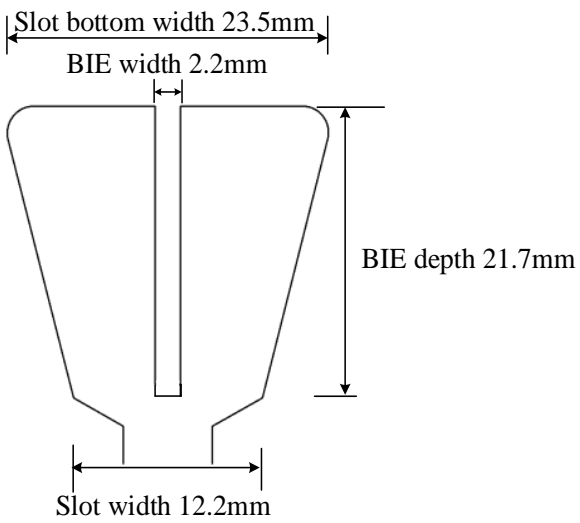

Fig. 1. Back-iron extension dimensions

TABLE

MACHINE GEOMETRY

\begin{tabular}{|c|c|c|c|c|}
\hline \multicolumn{3}{|c|}{ Machine Rating: } & \multicolumn{2}{|c|}{ Geometry: } \\
\hline Voltage & $\begin{array}{c}384 \\
V\end{array}$ & $\begin{array}{c}480 \\
V\end{array}$ & $\begin{array}{l}\text { Outer } \\
\text { diameter }\end{array}$ & $245 \mathrm{~mm}$ \\
\hline $\begin{array}{l}\text { Rated/peak } \\
\text { power }\end{array}$ & \multicolumn{2}{|c|}{$37 / 74 \mathrm{~kW}$} & $\begin{array}{l}\text { Active } \\
\text { length }\end{array}$ & $140 \mathrm{~mm}$ \\
\hline $\begin{array}{l}\text { Rated/peak } \\
\text { torque }\end{array}$ & \multicolumn{2}{|c|}{$\begin{array}{c}126 / 382 \\
\mathrm{Nm}\end{array}$} & $\begin{array}{l}\text { Coolant } \\
\text { temperature }\end{array}$ & $40 \sim 90^{\circ} \mathrm{C}$ \\
\hline Rated base speed & \multicolumn{2}{|c|}{$2800 \mathrm{rpm}$} & & \\
\hline $\begin{array}{l}\text { Working time at } \\
\text { peak power }\end{array}$ & \multicolumn{2}{|c|}{$\geqslant 60 \mathrm{~s}$} & & \\
\hline efficiency & \multicolumn{2}{|c|}{$95 \%$} & & \\
\hline Coolant & \multicolumn{2}{|c|}{ Water } & & \\
\hline \multicolumn{3}{|l|}{ Materials } & \multicolumn{2}{|c|}{$\begin{array}{l}\text { Thermal conductivity } \\
(\mathrm{W} / \mathrm{m} \cdot \mathrm{K})\end{array}$} \\
\hline Magnet & & $8 \mathrm{EH}$ & \multicolumn{2}{|c|}{7.6} \\
\hline \multirow{2}{*}{ Iron sheets } & \multirow{2}{*}{\multicolumn{2}{|c|}{$\begin{array}{l}\text { M235 } \\
-35\end{array}$}} & \multicolumn{2}{|c|}{ Radial: 30} \\
\hline & & & \multicolumn{2}{|c|}{ Axial: 0.27} \\
\hline Housing & \multicolumn{2}{|c|}{$\begin{array}{l}\text { Alumin } \\
\text { um }\end{array}$} & \multicolumn{2}{|c|}{180} \\
\hline Slot liner & \multicolumn{2}{|c|}{$\begin{array}{c}0.3 \mathrm{~mm} \\
\text { Nomex } \\
410\end{array}$} & \multicolumn{2}{|c|}{0.14} \\
\hline $\begin{array}{l}\text { Insulation (class } \\
\mathrm{H})\end{array}$ & \multicolumn{2}{|c|}{$\begin{array}{l}\text { Polyest } \\
\text { erimide }\end{array}$} & \multicolumn{2}{|c|}{0.21} \\
\hline
\end{tabular}

\section{A. ESTC calculation}

The equivalent slot thermal resistance is a critical and complex value for the copper loss heat transfer paths, which involves the analysis of the physical properties of the constituent materials within the slot, including the impregnation resin, insulation (enamel), copper, as well as slot liner placed between the coil and stator core, as shown in Fig. 2. A simple model to calculate the ESTC is proposed in this paper, which considers all the slot components in Fig. 2 together with the air bubbles due to the impregnation goodness. In the proposed model, ESTC is assumed uniform in the slot in the radial direction and the same number of square cell models replace the number of strands in the slot, with each cell described as shown in Fig. 3, i.e., one square cell per strand, with corresponding impregnation resin and air bubble proportion calculated on the area percentage basis. With equivalent component area percentages, the copper area percentage $\mathrm{p}_{1}$, insulation $\mathrm{p}_{2}$, impregnation resin $\mathrm{p}_{3}$, and air bubbles $\mathrm{p}_{4}$ are calculated with formulas from (1) to (4),

$$
\begin{gathered}
\mathrm{p}_{1}=\frac{\mathrm{s}_{\text {copper }}}{\mathrm{S}} \\
\mathrm{p}_{2}=\mathrm{p}_{1}\left[\left(1+\frac{l}{\mathrm{r}}\right)^{2}-1\right] \\
\mathrm{p}_{3}=\mathrm{G}\left(1-\mathrm{p}_{1}-\mathrm{p}_{2}\right) \\
\mathrm{p}_{4}=1-\mathrm{p}_{1}-\mathrm{p}_{2}-\mathrm{p}_{3}
\end{gathered}
$$

where ' $\mathrm{S}_{\text {copper }}{ }^{\prime}$ and ' $\mathrm{S}$ ' are the area of the copper and the slot (excluding the slot liner area), respectively. Furthermore, ' $l$ ' is the insulation thickness for each strand; ' $r$ ' is the strand copper radius; ' $G$ ' is the impregnation goodness, with value ranging from 0 corresponding to the situation of 'no impregnation', to 1 corresponding to a 'perfect impregnation' process (i.e. no air bubbles), respectively.

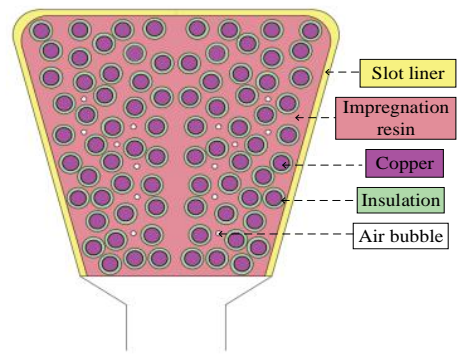

Fig. 2. Constituent materials inside the slot
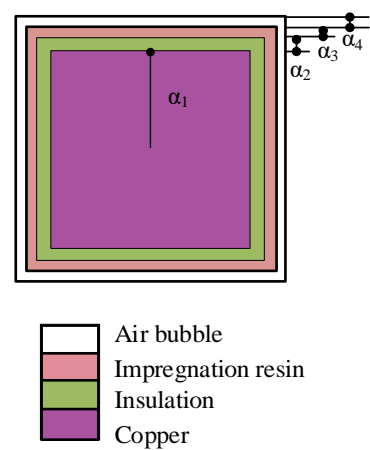

Fig. 3. Equivalent concentric squares geometric parameters for slot components

Based on the area percentage for each constituent material, the dimension for each component shown in Fig. 2 is calculated with formulas from (5) to (8),

$$
\alpha_{1}=\frac{\left(\mathrm{p}_{1} \mathrm{~S} / \mathrm{N}\right)^{0.5}}{2}
$$




$$
\begin{aligned}
& \alpha_{2}=\frac{\left(\left(\mathrm{p}_{1}+\mathrm{p}_{2}\right) \mathrm{S} / \mathrm{N}\right)^{0.5}}{2}-\frac{\left(\mathrm{p}_{1} \mathrm{~S} / \mathrm{N}\right)^{0.5}}{2} \\
& \alpha_{3}=\frac{\left(\left(\mathrm{p}_{1}+\mathrm{p}_{2}+\mathrm{p}_{3}\right) \mathrm{S} / \mathrm{N}\right)^{0.5}}{2} \\
& -\frac{\left(\left(\mathrm{p}_{1}+\mathrm{p}_{2}\right) \mathrm{S} / \mathrm{N}\right)^{0.5}}{2} \\
& \alpha_{4}=\frac{(\mathrm{S} / \mathrm{N})^{0.5}}{2}-\frac{\left(\left(\mathrm{p}_{1}+\mathrm{p}_{2}+\mathrm{p}_{3}\right) \mathrm{S} / \mathrm{N}\right)^{0.5}}{2}
\end{aligned}
$$

where $\mathrm{N}$ is total number of strands in the slot, $\alpha_{1}$ is the half length of the equivalent copper wire square, while $\alpha_{2}, \alpha_{3}$ and $\alpha_{4}$ are the equivalent thicknesses of insulation, impregnation resin, and air bubbles, respectively. Similar to the approach described in [15], trial segments are produced and cut for the observation of air bubbles in order to estimate the impregnation goodness.

For the radial effective thermal conductivity $\lambda_{\text {rad }}$ calculation, considering that the heat is transferred from one square cell to another square cell, with the areas of each component perpendicular to the heat flow assumed to be the same as $A_{\text {cont }}$,

$$
\begin{aligned}
& \mathrm{R}_{\mathrm{rad}}=\mathrm{R}_{\mathrm{cu}}+\mathrm{R}_{\mathrm{ins}}+\mathrm{R}_{\mathrm{imp}}+\mathrm{R}_{\mathrm{air}} \\
& \frac{l_{\text {rad }}}{\lambda_{\text {rad }} \mathrm{A}_{\text {cont }}}=\frac{l_{c u}}{\lambda_{\text {cu }} \mathrm{A}_{\text {cont }}}+\frac{l_{\text {ins }}}{\lambda_{\text {ins }} \mathrm{A}_{\text {cont }}} \\
& +\frac{l_{\text {imp }}}{\lambda_{\text {imp }} A_{\text {cont }}}+\frac{l_{\text {air }}}{\lambda_{\text {air }} A_{\text {cont }}} \\
& \begin{aligned}
\frac{\alpha_{1}+\alpha_{2}+\alpha_{3}+\alpha_{4}}{\lambda_{\text {rad }} A_{\text {cont }}} & =\frac{\alpha_{1}}{\lambda_{\text {cu }} A_{\text {cont }}}+\frac{\alpha_{2}}{\lambda_{\text {ins }} A_{\text {cont }}} \\
& +\frac{\alpha_{3}}{\lambda_{\text {imp }} A_{\text {cont }}}+\frac{\alpha_{4}}{\lambda_{\text {air }} A_{\text {cont }}}
\end{aligned} \\
& \frac{1}{\lambda_{\text {rad }}}=\frac{\mathrm{p}_{1}^{0.5}}{\lambda_{\text {cu }}}+\frac{\left(\mathrm{p}_{1}+\mathrm{p}_{2}\right)^{0.5}-\mathrm{p}_{1}^{0.5}}{\lambda_{\text {ins }}} \\
& +\frac{\left(\mathrm{p}_{1}+\mathrm{p}_{2}+\mathrm{p}_{3}\right)^{0.5}-\left(\mathrm{p}_{1}+\mathrm{p}_{2}\right)^{0.5}}{\lambda_{\text {imp }}} \\
& +\frac{1-\left(\mathrm{p}_{1}+\mathrm{p}_{2}+\mathrm{p}_{3}\right)^{0.5}}{\lambda_{\text {air }}}
\end{aligned}
$$

where $\mathrm{R}, l$ and $\lambda$ represent the thermal resistance, the component length and thermal conductivity respectively. The subscripts 'cu', 'ins', 'imp', 'air', represent copper, insulation, impregnation resin, and air bubbles, respectively.

In the calculation of the axial effective thermal conductivity $\lambda_{\text {axial }}$, all components are assumed to be parallel to the slot and to the heat flow direction.

$$
\lambda_{\text {axial }}=\lambda_{\text {cu }} \mathrm{p}_{1}+\lambda_{\text {ins }} \mathrm{p}_{2}+\lambda_{\text {imp }} \mathrm{p}_{3}+\lambda_{\text {air }} \mathrm{p}_{4}
$$

\section{B. Segments designed and thermal model}

Thermocouples installed in the original propulsion machine are placed to extract the peak winding temperature, which is a critical parameter to determine the maximum phase current and corresponding maximum output torque. However, for the original machine, being a production one, only a limited number of temperature sensors could be inserted, and hence the accurate temperature distribution within the stator cannot be obtained. Segments, therefore, based on the machine of TABLE 1, are developed to validate the thermal modelling more effectively, with multiple precisely-located thermocouples used to obtain an accurate temperature distribution and correlation to the thermal models.

Fig. 4 shows a stator segment (section corresponding to $1 / 4$ of full stator) developed for the thermal tests equipped with a plurality of thermocouples installed at sensitive locations, together with a specially designed water-cooling jacket. The thermocouple locations are detailed in Section III A. Compared to the copper losses, iron losses for the considered electrical machine are small and thus neglected in this paper. The stator segment is thus made of solid iron in order to simplify its manufacturing. Meanwhile during the thermal testing, the segment is thermally insulated from the ambient air using two layers of $6 \mathrm{~mm}$-thick CalciumMagnesium Silicate thermal insulation sheets in order to ensure that all the heat generated is dissipated to the back-iron and finally to the water jacket.

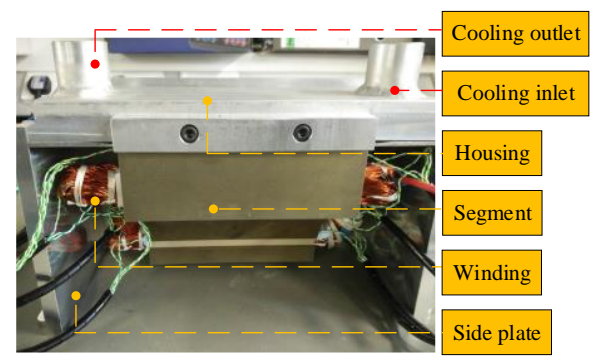

(a)

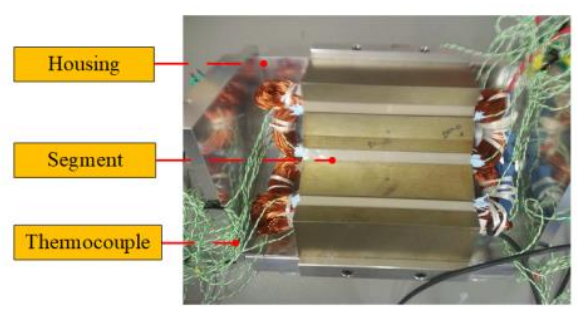

(b)

Fig. 4. Representative segments

A 3D lumped-parameter thermal network (LPTN) model of Fig. 4 is constructed for the test-segment with BIE shown in Fig. 5, considering both the radial and axial directions. In the thermal model for the segment, half slot together with the corresponding end-winding are simulated exploiting the machine symmetries. In the LPTN development process, sensitivity analysis on the number of nodes in the half slot is firstly conducted to investigate its relation to the temperature accuracy prediction. Fig. 6 shows the peak temperature variation 
against the nodes' number and indicates that 25 nodes are sufficient to accurately predict the temperature. Meanwhile, 25 nodes in the half slot are also able to provide the temperature distribution within the slot.

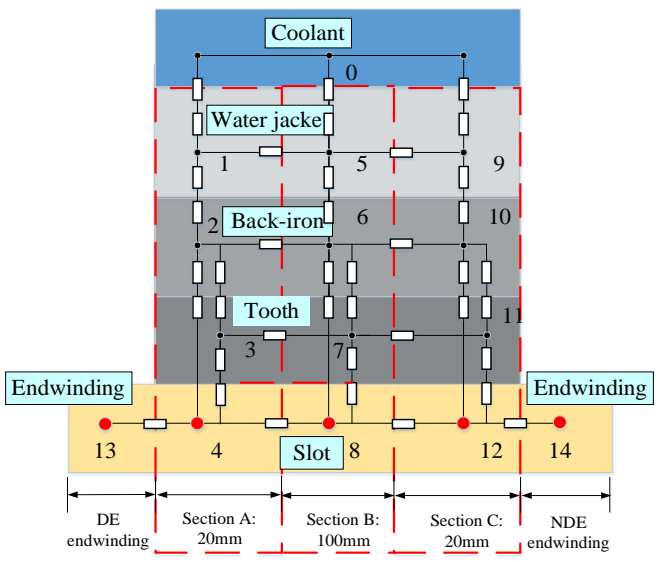

(a) axial section

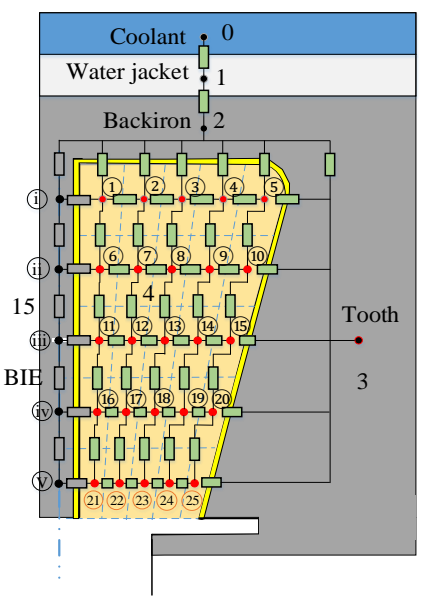

(b) radial 'Section A'

Fig. 5. 3D LPTN thermal model for the representative segment with BIE

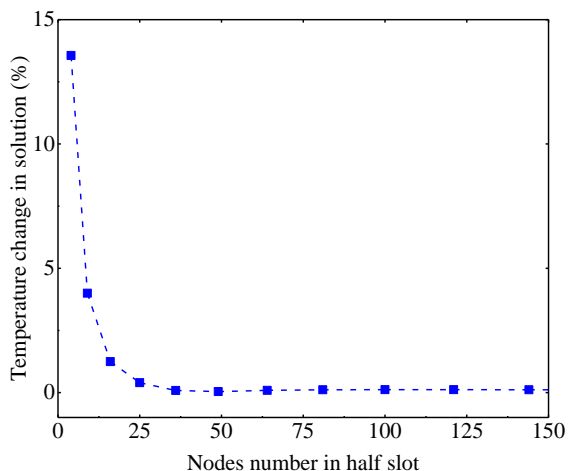

Fig. 6. Sensitivity analysis on number of nodes in the half slot
As shown in Fig. 5, there are 3 axial sections ('Section A',' Section B' and 'Section C') in the core part and two end-winding sections ('DE endwinding' and 'NDE end-winding'). It should be mentioned that in reality a further $5 \times 5$ nodes are distributed in Fig. 5 (b) sharing the same height in the half slot and BIE nodes in the back-iron, while only one node is shown in the half slot in Fig. 5 (a) for the sake of figure simplicity.

The slot thermal network is detailed in Fig. 5 (b), where the wedge shape near the opening is purposely designed for the segment in order to ensure the winding positions in the slot, without affecting the thermal performance of the segment. As can be seen from the same figure, there are 5 nodes placed in BIE, corresponding to the '5-layer' nodes in the slot with thermal resistances shaded in grey connecting 'BIE nodes' and slot nodes, as well as the back-iron node. A transient state thermal model can be derived with heat capacity and mass added to each node. The thermal model construction process for the original segment without BIE is conducted with infinitesimal values set for BIE dimensions.

The heat balance equation for each node ' $i$ ' in the thermal network in Fig. 5 is (14), where ' $n$ ' represents the total node number in the thermal network, except for the 'coolant' node. The 'coolant' temperature is considered constant as the temperature rise is small with a relative large flow rate and lower losses in the test section. Furthermore ' $\mathrm{j}$ ' represents the node that is adjacent to the studied node ' $\mathrm{i}$ ' . ' $\mathrm{T}_{\mathrm{i}}$ ' and ' $\mathrm{T}_{\mathrm{j}}$ ' are the node ' $\mathrm{i}$ ' and ' $\mathrm{j}$ ' temperatures, respectively, ' $\mathrm{R}_{\mathrm{ij}}{ }^{\prime}$ is the thermal resistance between node ' $i$ ' and ' $j$ ', while ' $q_{i}{ }^{\prime}$ is node ' $\mathrm{i}$ ' loss, and calculated on a volume percentage basis with formulas (15) and (16).

$$
\begin{gathered}
\mathrm{q}_{\mathrm{i}}+\sum_{\mathrm{j} \neq \mathrm{i}}^{\mathrm{n}} \frac{\mathrm{T}_{\mathrm{j}}-\mathrm{T}_{\mathrm{i}}}{\mathrm{R}_{\mathrm{ij}}}=0 \\
q_{i}=\frac{P_{\text {seg }}}{3 \times 2} \times \frac{l_{\text {sec }}}{L_{\text {seg-eq }}} \times \frac{A_{i}}{A_{\text {slot }}} \\
P_{\text {seg }}=\mathrm{I}_{\text {seg }}^{2} R_{\text {seg }}^{\prime}
\end{gathered}
$$

where ' $P_{\text {seg }}{ }^{\prime},{ }^{\prime} I_{\text {seg }}{ }^{\prime},{ }^{\prime}{ }_{\text {seg }}^{\prime}$ ' are the losses, current, and electrical resistance for the segment, respectively. The segment losses increase with the winding temperature due to increased electrical resistance and will be presented in detail in section III C. In (15) ' $l_{\text {sec }}$ ' is the length of the section where node ' $\mathrm{i}$ ' is located and ' $A_{i}{ }^{\prime}$ is the cross sectional area of node ' ${ }^{\prime}$ '. The parameter ${ }^{\prime} L_{\text {seg-eq }}$ ' is the half turn length, while ' $A_{\text {slot }}$ ' is the area of half a slot.

The thermal resistance ${ }^{\prime} R_{i j}$ ' in (14) consists of conduction thermal resistance in (17) and convection thermal resistance in (18), where ' $\lambda$ ' is the material thermal conductivity in $[\mathrm{W} /(\mathrm{m} \cdot \mathrm{K})],{ }^{\prime} l_{\text {con }}{ }^{\prime}$ is the node length parallel to the heat flow in [m], and ' $A_{\text {con }}{ }^{\prime}$ is the 
cross-sectional area perpendicular to the path of heat flow in $\left[\mathrm{m}^{2}\right]$. Conduction thermal resistance ' $R_{\text {con }}{ }^{\prime}$ is calculated with material properties and nodes' geometry, while the convection thermal resistance ' $R_{\text {conv }}$ ' is also linked with the fluid dynamics. In (18), $' h^{\prime}$ in $\left[\mathrm{W} /\left(\mathrm{m}^{2} \mathrm{~K}\right]\right.$ is the heat transfer coefficient and ' $A_{\text {conv }}$ ' is the convection area in $\left[\mathrm{m}^{2}\right]$.

$$
\begin{gathered}
R_{\text {con }}=\frac{l_{\text {con }}}{\lambda A_{\text {con }}} \\
R_{\text {conv }}=\frac{1}{h A_{\text {conv }}}
\end{gathered}
$$

For the thermal resistance calculation inside the slot, ' $\lambda$ ' is derived with the ESTC formulas presented earlier in section II A. For different electrical machines, employing different material recipes, the ESTC is a variable (i.e. the ESTC will change if any of the insulation materials are changed). For the purpose of this research and taking into account practical considerations, the slot liner thickness and material type are not changed, nor is the wire and impregnation goodness, since these are determined by the voltagerating, thermal-class and impregnation process. Impregnation goodness is affected by the material properties, such as resin viscosity and impregnation process. The vacuum pressure impregnation (VPI) system available within the lab, together with its appropriate tuning, is able to deliver fairly consistent impregnation goodness for the different resin materials considered. However a range of resins are available to the authors which correspond to different levels of ESTC. The ESTC correlation with the resin material is illustrated in Fig. 7.

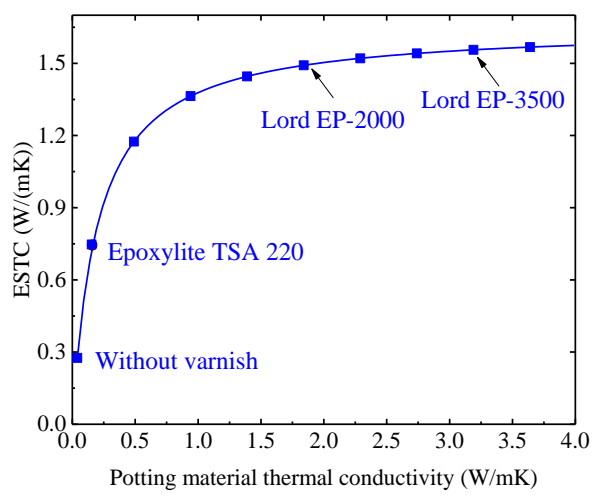

Fig. 7. ESTC variation with impregnation thermal conductivity

It can be seen from Fig. 7 that the ESTC is increasing quickly with the impregnation resin thermal conductivity and then the rate of rise decreases, as the value starts to be restricted by other constraints, such as the wire insulation properties and copper fill factor (0.4572). Epoxylite TSA220 with a thermal conductivity of $0.21 \mathrm{~W} /(\mathrm{m} \cdot \mathrm{K})$ is used for the varnished segments in this paper, which improves ESTC largely compared to the case without varnish as shown in Fig. 7. ESTC can be furtherly improved with premiumgrade higher thermal conductivity potting material, such as LORD EP-2000 $(1.9 \mathrm{~W} /(\mathrm{m} \cdot \mathrm{K}))$ and LORD EP$3500(3.3 \mathrm{~W} /(\mathrm{m} \cdot \mathrm{K}))$. Different potting material physical properties are listed in TABLE 2, including thermal conductivity and viscosity.

TABLE 2

POTTING MATERIAL PHYSICAL PROPERTIES

\begin{tabular}{|l|l|l|l|l|}
\hline $\begin{array}{l}\text { Potting } \\
\text { material }\end{array}$ & $\begin{array}{l}\text { Thermal } \\
\text { conductivity } \\
\left(\mathrm{W} \cdot \mathrm{m}^{-1} \cdot \mathrm{K}^{-1}\right)\end{array}$ & $\begin{array}{l}\text { Density } \\
\left(\mathrm{kg} / \mathrm{m}^{3}\right)\end{array}$ & $\begin{array}{l}\text { Viscosit } \\
\mathrm{y}(\mathrm{cps})\end{array}$ & $\begin{array}{l}\text { Coefficient } \\
\text { of Linear } \\
\text { Thermal } \\
\text { Expansion, } \\
\mathrm{ppm} /{ }^{\circ} \mathrm{C}\end{array}$ \\
\hline $\begin{array}{l}\text { Air } \\
\text { (without } \\
\text { varnish) }\end{array}$ & $\begin{array}{l}0.02587 @ \\
20^{\circ} \mathrm{C}\end{array}$ & $\begin{array}{l}1.29 \\
@ 21^{\circ} \mathrm{C}, \\
1 \mathrm{~atm}\end{array}$ & $\begin{array}{l}0.0181 \\
@ 15^{\circ} \mathrm{C}\end{array}$ & 3430 \\
\hline $\begin{array}{l}\text { Epoxylite } \\
\text { TSA220 }\end{array}$ & 0.21 & 1180 & 1250 & 50 \\
\hline $\begin{array}{l}\text { LORD } \\
\text { EP-2000 }\end{array}$ & 1.9 & 2730 & 1900 & 10.4 \\
\hline $\begin{array}{l}\text { LORD } \\
\text { EP-3500 }\end{array}$ & 3.3 & 2980 & 8000 & 14.9 \\
\hline
\end{tabular}

In the testing, the segment is thermally insulated from the ambient environment and thus all the heat generated within the segments can be considered to be removed by the water flowing inside the water jacket. The heat transfer coefficient inside the water jacket cooling channels is calculated with formulas (19) to (22) [26].

$$
\begin{gathered}
h=\lambda N u / D_{h} \\
R e=\rho v D_{h} / \mu \\
N u=\frac{(f / 8) \times(R e-1000) \times P r}{\left[1+12.7 \times(f / 8)^{0.5} \times\left(P^{2 / 3}-1\right)\right]} \\
f=(0.79 \times \ln (R e)-1.64)^{-2}, D_{h}= \\
4 S / P
\end{gathered}
$$

where ' $N u^{\prime}$, ' $R e^{\prime},{ }^{\prime} P r^{\prime}$, and ' $f^{\prime}$, are dimensionless parameter Nusselt number, Reynolds number, Prandtl number and friction factor, respectively. The parameters ' $\lambda$ ', ' $\rho$ ', and ' $\mu$ ' are the coolant thermal conductivity in $[\mathrm{W} /(\mathrm{m} \mathrm{K})]$, the mass density in $\left[\mathrm{kg} / \mathrm{m}^{3}\right]$ and the dynamic viscosity in $\left[\mathrm{kg} /\left(\mathrm{m}^{2} \mathrm{~s}\right)\right] .{ }^{\prime} D_{h}{ }^{\prime}$ is the hydraulic diameter of the cooling channel in $[\mathrm{m}]$, calculated from the cooling channel cross section area $' S^{\prime}$ in $\left[\mathrm{m}^{2}\right]$ and the wet peripheral length ${ }^{\prime} P^{\prime}$ in $[\mathrm{m}]$.

\section{ESTC thermal effects on BIE effectiveness}

The thermal conductivities' difference between the ESTC of the coil and that of the BIE material, along with the heat generated inside the slot are considered to affect the thermal benefits of applying BIE to electrical machines. With all other parameters maintained constant, Fig. 8 shows the tendency plot of the absolute peak winding temperature against ESTC for segments 
with and without BIE, using the model developed for the segments in section II B. In this figure, the ESTC ranges from 0.1 to $5 \mathrm{~W} /(\mathrm{m} \cdot \mathrm{K})$, considering the thermal conductivity of various commercially available resins for the thermal class considered. Three different current densities are investigated for this ESTC range: 6.13, 7.3 and $8.75 \mathrm{~A} / \mathrm{mm}^{2}$ in Fig. 8(a), while Fig. 8(b) plots the peak temperature variation against ESTC when segments with BIE and without are with the same copper losses.

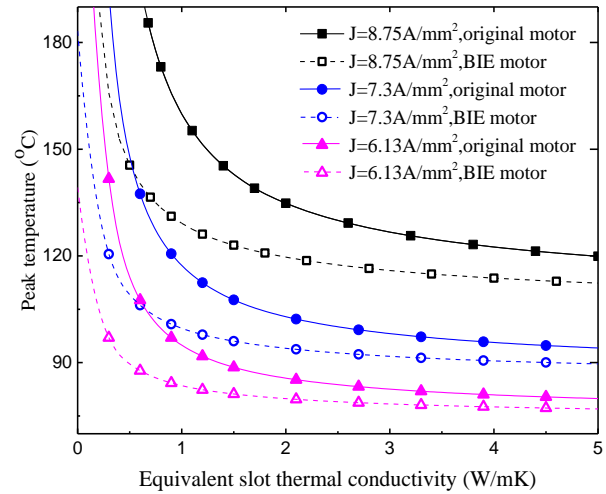

(a)

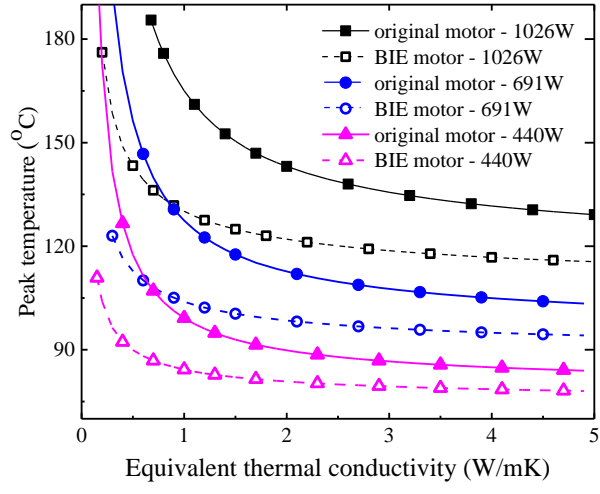

(b)

Fig. 8. Peak temperature tendency with ESTC for original motor segment and BIE segment

It can be observed from Fig. 8(a) that the peak winding temperature and current density are in positive correlation, and thermal improvement is achieved with BIE for each current density considered. For instance, for a current density of $8.75 \mathrm{~A} / \mathrm{mm}^{2}$, temperature benefit is deducible by the gap between the lines marked with solid and hollow markers, representing the original motor segment and the segment with BIE, respectively. It can be clearly seen from Fig. 8(a) that the smaller the ESTC is, the more significant the temperature reduction, i.e. the thermal benefit with BIE is, due to the larger thermal conductivities' difference between ESTC of the coil and BIE material. It also indicates that for the same BIE geometrical design, higher current density operation translates to larger thermal benefits.

For each curve set (with BIE and without BIE), it can be easily seen from Fig. 8(a) that the peak winding temperature first reduces sharply with ESTC, then it almost flattens out as the ESTC increases further. Indeed, for low values $(<2 \mathrm{~W} /(\mathrm{m} \cdot \mathrm{K}))$, ESTC is one of the critical factors in determining the thermal performances of the electrical machines and it is within this range that BIE exhibits the maximum effectiveness. For example, the temperature remains almost constant when the ESTC is increased over $1.4 \mathrm{~W} /(\mathrm{m} \cdot \mathrm{K})$, for the original motor segment with a current density of 6.13 $\mathrm{A} / \mathrm{mm}^{2}$. On the other hand, for the same original motor segment with a current density of $8.75 \mathrm{~A} / \mathrm{mm}^{2}$, when ESTC is over $2.5 \mathrm{~W} /(\mathrm{m} \cdot \mathrm{K})$, its effects on improving the thermal condition are not significant. From the foregoing discussion, as the operational current density increases (as is the trend with modern improved performance motors), the ESTC value up to which temperature reductions are more significant, increases as well.

\section{EXPERIMENTAL VALIDATION}

Simulations in the preceding section II indicate that the lower ESTC, which translates to poor slot thermal conditions, the larger the temperature reduction achieved with BIE. The observations are experimentally investigated in this section with constructed representative stator segments which are used with an instrumented test setup. As indicated in section II-A, there are various slot compositions which result into different ESTC. In the validation process, segments with impregnation and without, are used to represent different ESTC values and validate the preceding analysis.

\section{A. Segments}

The segments within this section are specifically designed for thermal analysis validation, with $1 / 4$ of the stator geometry. The $2.2 \mathrm{~mm}$-wide and full-slotdepth back-iron extension together with the surrounding ground-wall insulation take up space which would otherwise be available for the copper wires. Therefore, the copper area is reduced for the BIE segment which results in a higher resistance. A sample of a stator segment with BIE is 3D printed as shown in Fig.9 and used for winding trials in order to verify the slot copper fill factor.

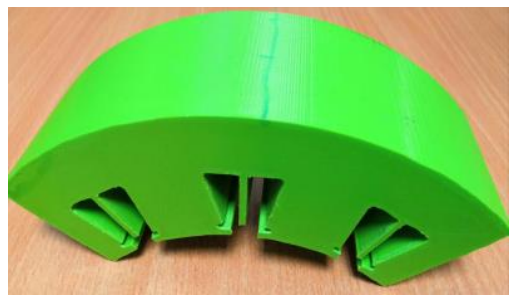

Fig. 9. Back-iron extension dummy stator for winding trials

After doing the winding trials for practical determination of copper slot fill factor, a stator segment with BIE is manufactured in solid iron. The winding arrangement in the segment is purposely designed for the thermal tests. For both segments with BIE and without, the number of turns are the same, while the 
reduced copper fill factor is reflected by the reduced strand number per turn.

Thermocouples (1) to (4)) are meticulously placed at specific locations to capture the temperature distribution within the segments' slots, with thermocouples (5) also glued on the stator iron surface to ensure that there is good and uniform contact between the segment and the housing, as shown in Fig. 10.

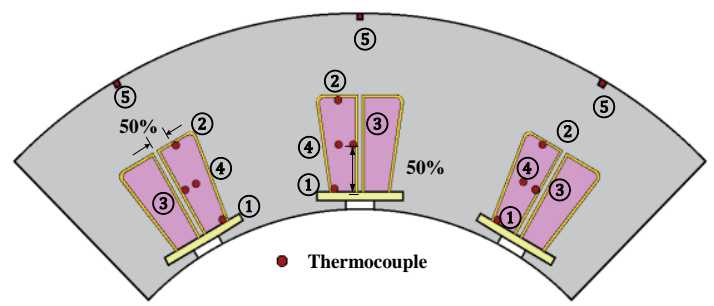

Fig. 10. Therocouple locations

In the first instance, the two segments, without BIE and with BIE shown are tested in the unvarnished condition as shown in Fig. 11 (a). The two segments are then varnished using a process of vacuum pressure impregnation (VPI) which ensures a good fill by the impregnation resin 'Epoxylite TSA 220' as shown in Fig. 11 (b). The varnished segments of Fig.11 (c) are subsequently retested.

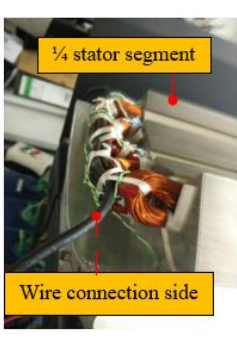

(a)

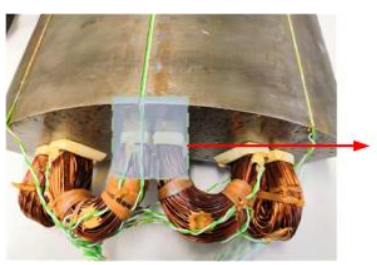

(c)

Fig. 11. Segment with BIE (a) Segment without varnish; (b) Segment just out from VPI without clearning; (c) varnished segment

\section{B. Experimental set up}

Using the test rig shown in Fig. 12, with constituent components including the segment under test shown in Fig.11, a DC power supply, Pico thermocouple data logger monitored by a PC, as well as cooling flow pipes attached to a water chiller. The segment is thermally insulated by Calcium-Magnesium Silicate thermal insulation sheets as shown in Fig. 12 to minimize any heat losses to the ambient environment and a heat flux sensor is applied to monitor any heat losses from the segment to the thermal insulation sheet, which are found to be negligible during the experiments. The inlet and outlet temperature are also measured to calculate the heat removed by the water jacket in comparison to the total input power from power supply, which proves that virtually no heat escapes from the segment other than to the water jacket.
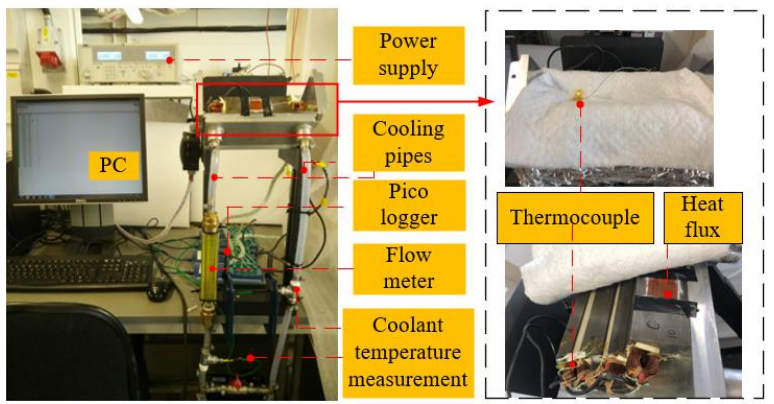

Fig. 12. Experimental test rig

Since next-generation high-power-density machines are copper loss dominant [2], the assumption that only DC losses are considered for the purpose of thermal management verification is considered valid and advantageous [6][25], since this simplifies the motorette construction, whilst eliminating the significant iron loss uncertainties due to the wellknown manufacturing effects [27]. Various DC currents are applied to the stator segment from a suitably rated power-supply for the segment thermal testing, following the testing procedure listed in TABLE 3. In test I and II, the two segments with BIE and without BIE are non-varnished. Under this unvarnished condition, the ESTC is around 0.3 $\mathrm{W} /(\mathrm{m} \cdot \mathrm{K})$, as shown in TABLE 3 derived from the formulas presented in Section II A. After the two segments are varnished in test III and IV, the same experimental tests with varying currents are repeated, and in this case the ESTC is around $0.685 \mathrm{~W} /(\mathrm{m} \cdot \mathrm{K})$. It can be seen that the ESTC improves markedly when the varnish is applied.

TABLE 3

EXPERIMENTAL TESTS

\begin{tabular}{|l|l|l|c|}
\hline Test & $\begin{array}{l}\text { Varnish } \\
\text { condition }\end{array}$ & Segment & $\begin{array}{c}\text { ESTC } \\
(\mathrm{W} / \mathrm{m} \cdot \mathrm{K})\end{array}$ \\
\hline Test I & $\begin{array}{l}\text { Without } \\
\text { varnish }\end{array}$ & $\begin{array}{l}\text { Original } \\
\text { segment }\end{array}$ & $\approx 0.3$ \\
\hline Test II & $\begin{array}{l}\text { Without } \\
\text { varnish }\end{array}$ & $\begin{array}{l}\text { BIE } \\
\text { segment }\end{array}$ & $\approx 0.3$ \\
\hline Test III & With varnish & $\begin{array}{l}\text { Original } \\
\text { segment }\end{array}$ & $\approx 0.7$ \\
\hline Test IV & With varnish & $\begin{array}{l}\text { BIE } \\
\text { segment }\end{array}$ & $\approx 0.7$ \\
\hline
\end{tabular}


The winding electrical resistance for both segments with BIE and without is derived from the current and voltage recorded with the DC power supply at room temperature before the segments are heated up. It is reported in TABLE 4 that BIE segment electrical resistance is slightly higher due to reduced copper fill factor. The differences between the calculated and experimental results are partially attributed to the electrical resistance existing in the wire connection for the practical segments.

TABLE 4

ELECTRICAL RESISTANCE CALCULATION AND MEASUREMENT

\begin{tabular}{|c|c|c|}
\hline \multirow{2}{*}{ Segment } & \multicolumn{2}{|c|}{ Winding electrical resistance $(\mathrm{m} \Omega)$} \\
\cline { 2 - 3 } & $\begin{array}{c}\text { Original } \\
\text { segment }\end{array}$ & BIE segment \\
\hline Experimental & 201 & 228 \\
\hline Calculated & $191(-5 \%)$ & $210.1(-7.8 \%)$ \\
\hline
\end{tabular}

\section{Experimental thermal results}

A series of experiments are conducted with various input currents for both the original and BIE segments as listed in TABLE 3. Due to the limitation of the wire insulation (class $\mathrm{H}$ ), the maximum temperature inside the slot is $180^{\circ} \mathrm{C}$.

Fig. 13, Fig. 14 and TABLE 5 show experimental results to verify the correlation between the BIE thermal effectiveness and ESTC. Fig. 13 plots the temperature variation versus input current, with different dots representing the experimentallymeasured results, while the different dashed lines represent the simulation results. The thermal results from the experiments agree well with the simulation, with slight temperature deviation which can be attributed to the following reasons: (i) the thermocouple locations; (ii) deviations in deriving parameters for the thermal network, such as thermal conductivity calculation deviations due to the materials' range of thermal conductivities given in the datasheet; (iii) ESTC is assumed uniform in the thermal network while the equivalent thermal conductivity is not uniform in practice due to the material properties of different slot components; (iv) measurement uncertainties. For both the two conditions (varnished/unvarnished) in TABLE 3, temperature reduction is observed for the segment with BIE. It can be clearly seen from Fig. 13 that for the same thermal limit of $130^{\circ} \mathrm{C}$ (temperature rise) with $50^{\circ} \mathrm{C}$ coolant temperature, the maximum experimental input current for original segment with varnish and without is $30.4 \mathrm{~A}\left(8.75 \mathrm{~A} / \mathrm{mm}^{2}\right)$ and $25 \mathrm{~A}\left(7.3 \mathrm{~A} / \mathrm{mm}^{2}\right)$.

To provide a clear correlation between temperature reduction with BIE and ESTC, Fig. 14 is derived from Fig. 13 and Fig. 8. The correlation between the ESTC and the temperature reduction achieved by BIE is plotted, for current densities of $6.13 \mathrm{~A} / \mathrm{mm}^{2}, 7.3$
$\mathrm{A} / \mathrm{mm}^{2}$ and $8.75 \mathrm{~A} / \mathrm{mm}^{2}$. For the segments without varnish (i.e. $E S T C \approx 0.3$ ) and with varnish (i.e. $\mathrm{ESTC} \approx 0.7$ ), the temperature reduction from the experimental results is marked with dots in Fig. 14, which shows a good match with the predicted temperature reduction from the thermal model.

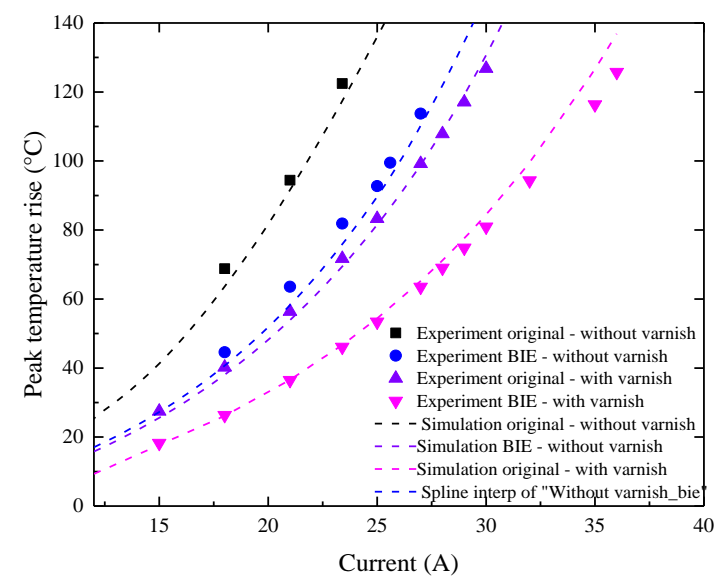

Fig. 13. Peak temperature variation with current

For a current density of $6.13 \mathrm{~A} / \mathrm{mm}^{2}$, temperature reductions of $20^{\circ} \mathrm{C}$ and $34^{\circ} \mathrm{C}$ are observed for segments with BIE under varnished and un-varnished conditions (lower ESTC), respectively, as indicated in Fig. 14. It is, therefore, verified that the BIE is more effective for lower ESTC. The same phenomenon can be observed in a more pronounced way when the current density increases to $7.3 \mathrm{~A} / \mathrm{mm}^{2}$, for which temperature reductions of $30^{\circ} \mathrm{C}$ and $54^{\circ} \mathrm{C}$ are measured for segments with varnish and without, respectively. The corresponding results are listed in TABLE 6 to provide the readers a clear view of the BIE effectiveness corresponding to different ESTC. For each current density, more significant temperature reduction is achieved with BIE for the cases with lower ESTC.

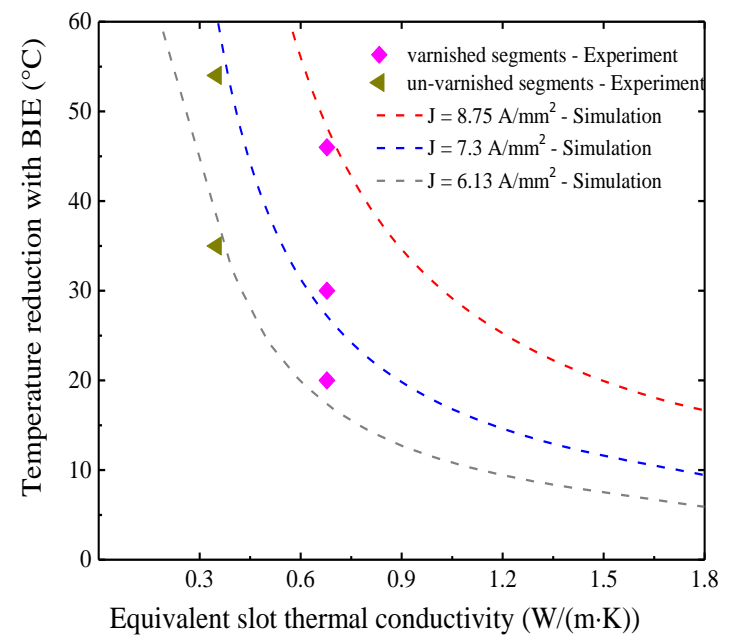

Fig. 14. Experimental validation for ESTC thermal effects on BIE effectiveness 
TABLE 5 TEMPERATURE COMPARISON IN THE SLOT (25A)

\begin{tabular}{|c|c|c|c|c|c|c|c|}
\hline \multirow{2}{*}{ Test } & \multirow{2}{*}{\multicolumn{2}{|c|}{ Segment }} & \multicolumn{5}{|c|}{ Temperature comparison } \\
\hline & & & & $\mathrm{TC} 1\left({ }^{\circ} \mathrm{C}\right)$ & $\mathrm{TC} 2\left({ }^{\circ} \mathrm{C}\right)$ & $\mathrm{TC} 3\left({ }^{\circ} \mathrm{C}\right)$ & $\mathrm{TC} 4\left({ }^{\circ} \mathrm{C}\right)$ \\
\hline \multirow{2}{*}{ Test I } & \multirow{2}{*}{$\begin{array}{l}\text { Original } \\
\text { segment } \\
\text { without } \\
\text { varnish }\end{array}$} & \multirow[b]{2}{*}{ (1) } & Experiment & 106 & 104 & 179.5 & / \\
\hline & & & Simulation & $\begin{array}{c}102 \\
(-3.8 \%)\end{array}$ & $\begin{array}{c}103 \\
(-1 \%)\end{array}$ & $\begin{array}{c}178.6 \\
(-0.5 \%)\end{array}$ & 162 \\
\hline \multirow{2}{*}{ Test II } & \multirow{2}{*}{$\begin{array}{l}\text { BIE } \\
\text { segment } \\
\text { without } \\
\text { varnish }\end{array}$} & & Experiment & 96 & 107 & 115 & 125 \\
\hline & & & Simulation & $\begin{array}{c}92 \\
(-4.2 \%)\end{array}$ & $\begin{array}{c}99.3 \\
(-7.2 \%)\end{array}$ & $\begin{array}{c}119 \\
(3.5 \%)\end{array}$ & $\begin{array}{c}126 \\
(0.8 \%)\end{array}$ \\
\hline \multirow{2}{*}{ Test III } & \multirow{2}{*}{$\begin{array}{l}\text { Original } \\
\text { segment } \\
\text { with } \\
\text { varnish }\end{array}$} & \multirow[b]{2}{*}{ (1) } & Experiment & 94 & 80 & 120 & l \\
\hline & & & Simulation & $\begin{array}{c}92.7 \\
(-1.4 \%)\end{array}$ & $\begin{array}{c}89 \\
(11.25 \%)\end{array}$ & $\begin{array}{c}119 \\
(-0.8 \%)\end{array}$ & 112 \\
\hline \multirow{2}{*}{ Test IV } & \multirow{2}{*}{$\begin{array}{l}\text { BIE } \\
\text { segment } \\
\text { with } \\
\text { varnish }\end{array}$} & \multirow[b]{2}{*}{ 1 } & Experiment & 86.1 & 90 & 92 & 95.3 \\
\hline & & & Simulation & $\begin{array}{c}84 \\
(-2.4 \%)\end{array}$ & $\begin{array}{c}81 \\
(-10 \%)\end{array}$ & $\begin{array}{c}94 \\
(2.2 \%)\end{array}$ & $\begin{array}{c}95 \\
(-0.3 \%)\end{array}$ \\
\hline
\end{tabular}

TABLE 6

EXPERIMENTALLY MEASURED BIE EFFECTIVENESS WITH VARIOUS ESTC

\begin{tabular}{|l|l|l|}
\hline $\begin{array}{l}\text { Current } \\
\text { density } \\
\left(\mathrm{A} / \mathrm{mm}^{2}\right)\end{array}$ & $\begin{array}{l}\text { Various } \\
\text { ESTC }\end{array}$ & $\begin{array}{l}\text { BIE thermal effectiveness } \\
\text { (temperaure reduction }{ }^{\circ} \mathrm{C} \\
\text { achieved with BIE } \\
\text { compared to segment } \\
\text { without) }\end{array}$ \\
\hline 6.13 & $\begin{array}{l}\text { Un-varnished } \\
\text { segmets } \\
(\text { ESTC } \approx 0.3)\end{array}$ & 34 \\
\cline { 2 - 3 } & $\begin{array}{l}\text { Varnished } \\
\text { segments } \\
(\text { ESTC } \approx 0.7)\end{array}$ & \\
\hline \multirow{5}{*}{7.3} & $\begin{array}{l}\text { Un-varnished } \\
\text { segmets } \\
(\text { ESTC } \approx 0.3)\end{array}$ & \\
\cline { 2 - 3 } & $\begin{array}{l}\text { Varnished } \\
\text { segments } \\
(\text { ESTC } \approx 0.7)\end{array}$ & 20 \\
\hline
\end{tabular}

For reference TABLE 7 list the losses for the segments during the aforementioned experimental tests. Corresponding to the higher electrical resistance with BIE in TABLE 4, the losses for segment with BIE are higher for the same current when the current is small and the BIE thermal benefits are not obvious. However, when the current is large, the significant temperature reduction achieved with BIE starts to outweigh the reduced fill factor, and a net reduction in copper losses can be observed.

TABLE 7

SEGMENT LOSSES

\begin{tabular}{|c|c|c|c|c|}
\hline \multirow{2}{*}{$\begin{array}{l}\text { Current } \\
\text { (A) }\end{array}$} & \multicolumn{2}{|c|}{$\begin{array}{l}\text { Unvarnished } \\
\text { segment losses (W) }\end{array}$} & \multicolumn{2}{|c|}{$\begin{array}{l}\text { Varnished segment } \\
\text { losses (W) }\end{array}$} \\
\hline & $\begin{array}{l}\text { Original } \\
\text { segment }\end{array}$ & BIE & $\begin{array}{l}\text { Original } \\
\text { segment }\end{array}$ & BIE \\
\hline 15 & 59.3 & 62.5 & 57.3 & 61.1 \\
\hline 18 & 89.4 & 93.0 & 85.2 & 89.9 \\
\hline 21 & 129.2 & 131.3 & 120.6 & 125.7 \\
\hline 23.4 & 169 & 169.4 & 155.2 & 160.0 \\
\hline 25 & 201 & 199 & 181.9 & 186.0 \\
\hline 27 & \multirow{7}{*}{$*$} & 240.9 & 219.7 & 222.4 \\
\hline 28 & & 264.8 & 240.7 & 242.3 \\
\hline 29 & & 290.7 & 263.4 & 263.5 \\
\hline 30 & & \multirow{4}{*}{$*$} & 287.7 & 286.1 \\
\hline 32 & & & \multirow{3}{*}{ * } & 335.6 \\
\hline 35 & & & & 422.0 \\
\hline 36 & & & & 456.1 \\
\hline
\end{tabular}


The thermal performance improvement of BIE for un-varnished and varnished segments can be seen from the temperature contours of Fig. 15 and Fig. 16 obtained from the validated thermal model, corresponding to the experimental cases shown in Fig. 14 with current density of $7.3 \mathrm{~A} / \mathrm{mm}^{2}(25 \mathrm{~A})$ and ESTC equal to $\sim 0.3 \quad \mathrm{~W} /(\mathrm{m} \cdot \mathrm{K})$ and $\sim 0.7 \quad \mathrm{~W} /(\mathrm{m} \cdot \mathrm{K})$, respectively. The benefits of using BIE can be observed from both Fig. 15 and Fig. 16 in that the hot spot, which is in the center of the slot for the original segment, moves to the center of the half slot for the segment with BIE and the maximum temperature is significantly reduced for both the un-varnished and varnished conditions.

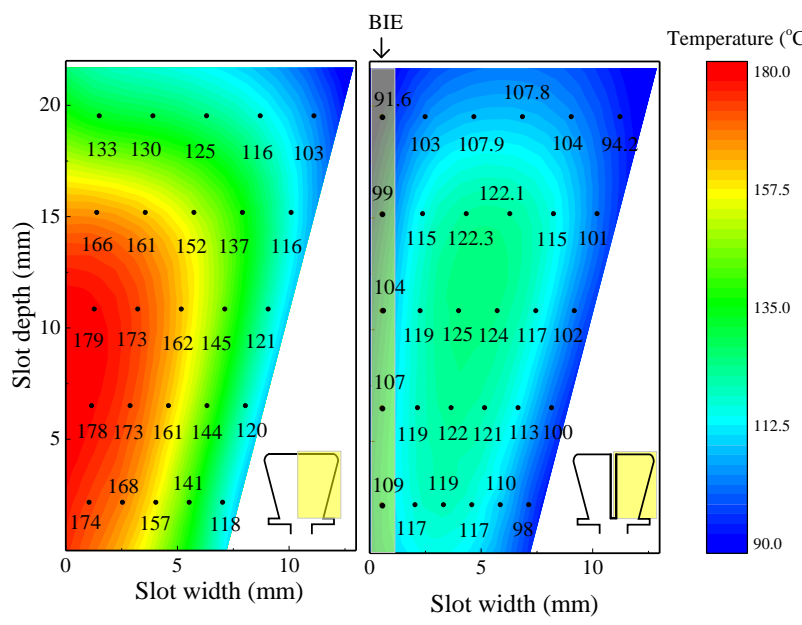

(a) original segment

(b) segment with BIE

Fig. 15. Temperature contour in half slot for segments without varnish

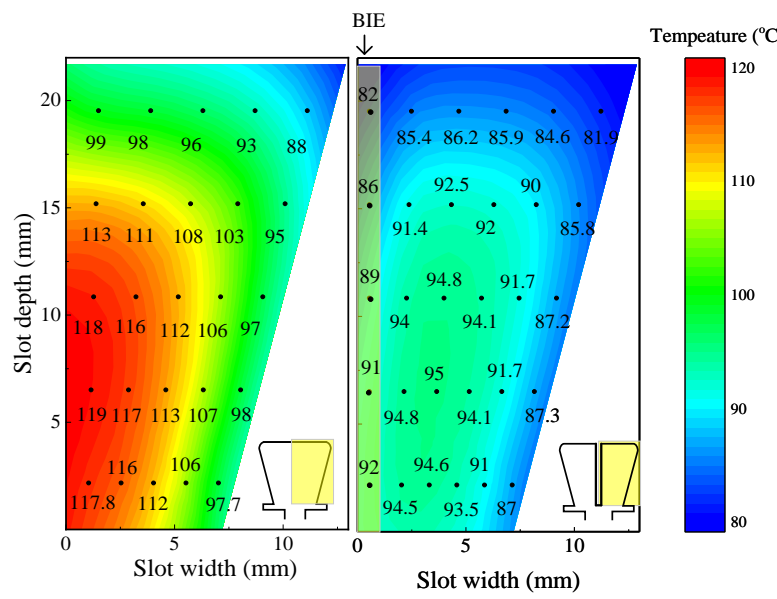

$\begin{array}{ll}\text { (a) original segment } & \text { (b) segment with BIE }\end{array}$

Fig. 16. Temperature contour in half slot for varnished segments

With the peak temperature in Fig. 16 (a) and Fig. 15 (a) compared, it can be seen that the slot thermal condition is largely improved by the varnishing process with improved ESTC value. A further temperature reduction can be achieved with BIE applied, as seen in Fig. 16.

It is also clearly seen that more pronounced temperature reduction with BIE is observed for the unvarnished segments with low ESTC.

\section{CONCLUSION}

Improved thermal management is an important performance enabler for next generation high power density electrical machines, leading to various ongoing parallel research avenue activities on this topic. While most enhanced cooling methodologies involve either higher material costs, additional auxiliaries, or more complicated processes, back-iron extension (BIE) is reported recently as an effective zero-cost improvement since it mainly requires suitable design of the lamination punching tool before series motor production.

The BIE geometry needs to be carefully tailored considering the thermal benefits it brings together with several multi-domain aspects. BIE takes up space in the slot which would otherwise be available for copper, extra iron losses are generated within, and it also increases the flux leakage, hence the current to maintain a reference output torque also increases. It should be noted that for higher frequency machines than the one studied in this paper, the benefits or otherwise of using a BIE should be checked also taking into account any additional winding $\mathrm{AC}$ losses due to the increased slot leakage flux, together with techniques to reduce such losses, such as conductor transposition. These are pivotal considerations when determining the suitability (and optimization) of BIE geometries, which for propulsion applications need to be studied in combination with the electrification architecture and the key motor residency (load) points.

From a manufacturing perspective, BIE can be easily integrated in the stator lamination punching process. Nevertheless based on the coil-winding manufacturing strategy, for example use of needle winding, or use of preformed coils, further specific production-related adjustments may be needed, for example adoption of thinner wire or the use of an increased slot opening. Mechanical checks should also be conducted to make sure the BIE does not deform during the winding process.

As a key contribution this paper has quantified through reproducible analytical/experimental methods, the relationship between the back-iron extension effectiveness and the equivalent slot thermal conductivity (ESTC). The ESTC values are derived based on commercially available materials which readers may encounter in their day-to-day work. Results show that the lower the equivalent slot thermal conductivity for the electrical machine is, the larger the thermal benefits the back-iron extension brings: $48^{\circ} \mathrm{C}$ temperature reduction down to $18^{\circ} \mathrm{C}$ temperature reduction across the plausible ESTC range investigated 
from $0.7 \mathrm{~W} / \mathrm{m} \cdot \mathrm{K}$ up to $1.8 \mathrm{~W} / \mathrm{m} \cdot \mathrm{K}$. Furthermore, for a given ESTC the BIE thermal benefits increase as the current loading increases.

It is concluded from this research that for electrical machines with lower equivalent slot thermal conductivity, which can be due to reasons such as, material cost constraints, limited available resins for a specific high temperature class, low copper fill factor due to coil-winding machinery, use of wire grades with thicker enamel, etc. more significant thermal benefits can be achieved with back-iron extension.

\section{REFERENCES}

[1] D. Gerada, X. Huang, C. Zhang, H. Zhang, X. Zhang, and C. Gerada, "Electrical machines for automotive electrically assisted turbocharging," IEEE/ASME Transactions on Mechatronics, vol. 23, no. 5, pp. 2054-2065, 2018.

[2] D. Golovanov, L. Papini, D. Gerada, Z. Xu, and C. Gerada, "Multidomain Optimization of High-Power-Density PM Electrical Machines for System Architecture Selection," IEEE Transactions on Industrial Electronics, vol. 65, no. 7, pp. 53025312, 2018.

[3] G. Sugden, "Oil-cooled ac generators for aircraft-present trends," Students' Quarterly Journal, vol. 40, no. 160, pp. 128$133,1970$.

[4] L. Kung, U. Bikle, O. Popp, and R. Jakoby, "Improvement of the cooling performance of symmetrically self-ventilated induction machines in the 2-15 MW range," in IEMDC 2001. IEEE International Electric Machines and Drives Conference (Cat. No.01EX485), 17-20 June 2001 2001, pp. 673-680, doi: 10.1109/IEMDC.2001.939386.

[5] A. Acquaviva, O. Wallmark, E. A. Grunditz, S. T. Lundmark, and T. Thiringer, "Computationally efficient modeling of electrical machines with cooling jacket," IEEE Transactions on Transportation Electrification, vol. 5, no. 3, pp. 618-629, 2019.

[6] F. Zhang et al., "Back-Iron Extension Thermal Benefits for Electrical Machines With Concentrated Windings," IEEE Transactions on Industrial Electronics, vol. 67, no. 3, pp. 17281738, 2020, doi: 10.1109/TIE.2019.2903758.

[7] T. Dong, C. Zhu, F. Zhou, H. Zhang, F. Lu, and X. Zhang, "Innovated Approach of Predictive Thermal Management fo High-Speed Propulsion Electric Machines in More Electric Aircraft," IEEE Transactions on Transportation Electrification, vol. 6, no. 4, pp. 1551-1561, 2020, doi 10.1109/TTE.2020.3017764

[8] W. Jiang and T. M. Jahns, "Coupled Electromagnetic-Thermal Analysis of Electric Machines Including Transient Operation Based on Finite-Element Techniques," IEEE Transactions on Industry Applications, vol. 51, no. 2, pp. 1880-1889, 2015, doi: 10.1109/TIA.2014.2345955.

[9] J. Li, Y. Lu, Y. Cho, and R. Qu, "Design, Analysis and Prototyping of a Water-Cooled Axial Flux Permanent Magnet Machine for Large Power Direct-Driven Applications," IEEE Transactions on Industry Applications, pp. 1-1, 2019, doi: 10.1109/TIA.2019.2907890

[10]X. Fan, D. Li, R. Qu, and C. Wang, "A Dynamic Multilayer Winding Thermal Model for Electrical Machines With Concentrated Windings," IEEE Transactions on Industrial Electronics, vol. 66, no. 8, pp. 6189-6199, 2019, doi: 10.1109/TIE.2018.2875634.

[11] R. J. Wang and G. C. Heyns, "Thermal analysis of a watercooled interior permanent magnet traction machine," in 2013 IEEE International Conference on Industrial Technology (ICIT), 25-28 Feb. 2013 2013, pp. 416-421, doi: 10.1109/ICIT.2013.6505708.

[12]L. Ye, D. Li, Y. Ma, and B. Jiao, "Design and Performance of a Water-cooled Permanent Magnet Retarder for Heavy Vehicles," IEEE Transactions on Energy Conversion, vol. 26, no. 3, pp. 953-958, 2011, doi: 10.1109/TEC.2011.2157347.
[13]C. Kral, A. Haumer, and T. Bauml, "Thermal Model and Behavior of a Totally-Enclosed-Water-Cooled Squirrel-Cage Induction Machine for Traction Applications," IEEE Transactions on Industrial Electronics, vol. 55, no. 10, pp. 35553565, 2008, doi: 10.1109/TIE.2008.927242.

[14]N. Simpson, R. Wrobel, and P. H. Mellor, "Estimation of equivalent thermal parameters of impregnated electrical windings," IEEE Transactions on Industry Applications, vol. 49, no. 6, pp. 2505-2515, 2013.

[15]S. Nategh, A. Krings, O. Wallmark, and M. Leksell, "Evaluation of impregnation materials for thermal management of liquidcooled electric machines," IEEE Transactions on Industrial Electronics, vol. 61, no. 11, pp. 5956-5965, 2014.

[16]D. J. Powell, "Modelling of high power density electrical machines for aerospace," University of Sheffield, 2004.

[17]S. A. Semidey and J. R. Mayor, "Experimentation of an Electric Machine Technology Demonstrator Incorporating Direct Winding Heat Exchangers," IEEE Trans. Industrial Electronics, vol. 61, no. 10, pp. 5771-5778, 2014.

[18]W. J. Chen Xiao, Griffo A., Spagnolo A., "Thermal Modelling of Hollow Conductors for Direct Cooling of Electrical Machines," IEEE Transactions on Industrial Electronics, 2019.

[19] G. Venturini, G. Volpe, M. Villani, and M. Popescu, "Investigation of Cooling Solutions for Hairpin Winding in Traction Application," in 2020 International Conference on Electrical Machines (ICEM), 23-26 Aug. 2020 2020, vol. 1, pp. 1573-1578, doi: 10.1109/ICEM49940.2020.9271026.

[20]W. Sixel, M. Liu, G. Nellis, and B. Sarlioglu, "Cooling of Windings in Electric Machines via 3D Printed Heat Exchanger," IEEE Transactions on Industry Applications, pp. 1-1, 2020, doi: 10.1109/TIA.2020.2997902.

[21]P. Lindh et al., "Direct liquid cooling method verified with an axial-flux permanent-magnet traction machine prototype," IEEE Transactions on Industrial Electronics, vol. 64, no. 8, pp. 60866095, 2017

[22]T. Davin, J. Pellé, S. Harmand, and R. Yu, "Experimental study of oil cooling systems for electric motors," Applied Thermal Engineering, vol. 75, pp. 1-13, 2015.

[23] L. Zhenguo, L. Shaoyan, and R. Lin, "The effect of spray parameter on heat dissipation in spray evaporatvie cooling high power density motors," in Electrical Machines and Systems (ICEMS), 2017 20th International Conference on, 2017: IEEE, pp. 1-4.

[24] J.-y. Jia, Y.-x. Guo, W.-d. Wang, and S.-r. Zhou, "Modeling and experimental research on spray cooling," in 2008 Twenty-fourth Annual IEEE Semiconductor Thermal Measurement and Management Symposium, 2008: IEEE, pp. 118-123.

[25]C. Liu et al., "Experimental Investigation on Oil Spray Cooling with Hairpin Windings," IEEE Transactions on Industrial Electronics, pp. 1-1, 2019, doi: 10.1109/TIE.2019.2942563.

[26]V. Gnielinski, "New equations for heat and mass transfer in turbulent pipe and channel flow," Int. Chem. Eng., vol. 16, no. 2, pp. 359-368, 1976.

[27] A. Al-Timimy, G. Vakil, M. Degano, P. Giangrande, C. Gerada, and M. Galea, "Considerations on the effects that core material machining has on an electrical machine's performance," IEEE Transactions on Energy Conversion, vol. 33, no. 3, pp. 11541163,2018

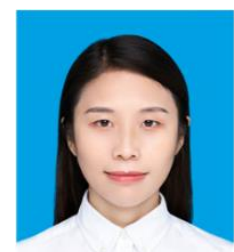

Fengyu Zhang received B.E degree in thermal engineering from Huazhong University of Science and Technology, Wuhan, China in 2014 and Ph.D. degree in electrical machines from University of Nottingham in 2019.

She is currently a Research Fellow in the area of thermal management on electrical machines within the PEMC group at University of Nottingham. Her main research interests include high performance motors for transport applications and their multi-domain optimization. 


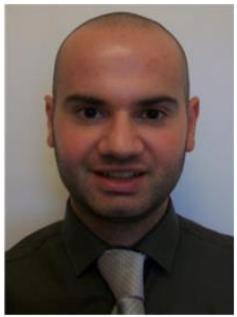

David Gerada (Senior Member, IEEE) received the Ph.D. degree in high-speed electrical machines from University of Nottingham, Nottingham, U.K., in 2012

From 2007 to 2016, he was with the R\&D Department at Cummins, Stamford, U.K., first as an Electromagnetic Design Engineer (2007-2012), and then as a Senio Electromagnetic Design Engineer and Innovation Leader (2012- 2016). At Cummins, he pioneered the design and development of high-speed electrical machines, transforming a challenging technology into a reliable one suitable for the transportation market, while establishing industry-wide-used metrics for such machinery. In 2016, he joined the University of Nottingham where he is currently a Principal Research Fellow, responsible for developing state-of-the-art electrical machines for future transportation which push existing technology boundaries, while propelling the new technologies to higher technology readiness levels.

Dr. Gerada is a Chartered Engineer in the U.K. and a member of the Institution of Engineering and Technology.

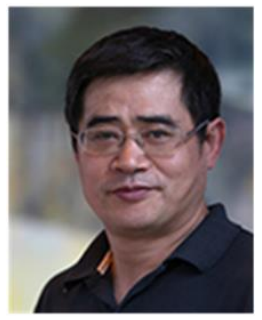

Zeyuan Xu received the Ph.D. degree in mechanical engineering from the University of Manchester, Manchester, U.K., in 2002.

He subsequently worked as a Research Fellow at UMIST, Brunel University, and University of Nottingham. He is currently a Senior Research Fellow in thermomechanical design of high speed electrica machines within the PEMC group at University of Nottingham, Nottingham, U.K. His main research interests include turbulent thermo-fluid flow, heat transfer enhancement, and thermal management of advanced electrical machines and power electronics.

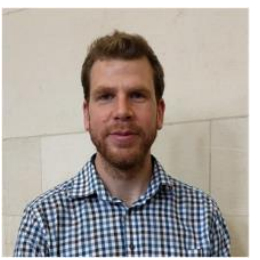

Chris Tighe received the MEng and Ph.D degrees in mechanical engineering from the University of Nottingham, U.K., in 2007 and 2011, respectively.

He worked in the electrical generator industry and in various research and commercial machine development positions at the University of Nottingham. $\mathrm{He}$ is now the proprietor of Electrical Cooling Solutions, an engineering design consultancy specialising in the thermal management of electrical machines and power electronics.

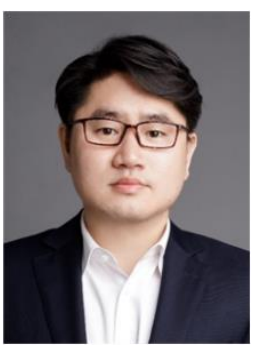

He Zhang (Senior Member, IEEE) received his B.Eng. degree from Zhejiang University, China, in 2002. He obtained the MSc. and Ph.D. degree in electrical machines from The University of Nottingham, UK, in 2004 and 2009 respectively.

He worked as Research Fellow at the University and Director of BestMotion Technology Centre, Nottingham, UK. He moved to University of Nottingham Ningbo China as Senior Research Fellow in 2014, promoted to Principal Research Fellow in 2016 and to Professor in 2020.He is currently the Director of Nottingham Electrification Centre (NEC) within the Power electronics, Machines and Control research group in University of Nottingham Ningbo China. His research interests include high performance electric machines and drives for transport electrification.

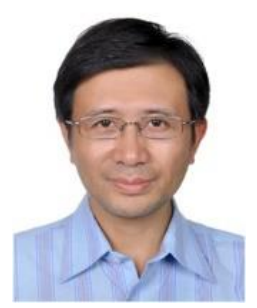

Liang Yan received B.S., M.S. and Ph.D degrees from North China Institute of Technology, Beijing Institude of Technology (BIT), China, and Nanyang Technology University (NTU), Singapore, respectively. He was with BIT from 1998 to 2002 and with NTU from 2006 to 2009 . He is currently a Professor with Beihang University, Beijing, China.

His main research interests include actuators, robotics and sensors. He served more than ten IEEE/ASME conferences as the Program and Publication Chairman.

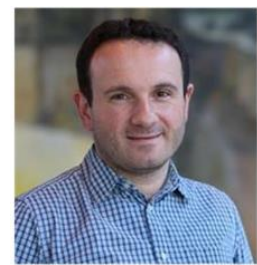

Chris Gerada (Senior Member, IEEE) received the Ph.D. degree in numerical modelling of electrical machines from the University of Nottingham, Nottingham, U.K., in 2005.

He worked as a Researcher with the University of Nottingham, on highperformance electrical drives and the design and modeling of electromagnetic actuators for aerospace applications. In 2008, he was appointed as a Lecturer of Electrical Machines, in 2011, as an Associate Professor, and in 2013, as a Professor with the University of Nottingham. He is currently an Associate Pro-Vice-Chancellor of Industrial Strategy and Impact and a Professor of Electrical Machines with the University of Nottingham, UK. He has secured over £20M of funding through major industrial, European, and U.K. grants and authored more than 350 referred publications. His principal research interest lies in electromagnetic energy conversion in electrical machines and drives, focusing mainly on transport electrification.

Prof. Gerada was awarded a Research Chair from the Royal Academy of Engineering in 2013. He served as an Associate Editor for the IEEE TRANSACTIONS ON INDUSTRY APPLICATIONS and is the past Chair of the IEEE IES Electrical Machines Committee. 